\title{
ANALISIS NILAI DAN KUALITAS RUANG MENGGUNAKAN PENDEKATAN KRITERIA TAK TERUKUR PADA KAWASAN KAMPUNG BATIK KAUMAN SEBAGAI KAWASAN WISATA BUDAYA KOTA PEKALONGAN
}

\author{
Nofa Martina Ariani ${ }^{1)}$, Muhammad Indra Hadi Wijaya ${ }^{2)}$, Bagus Nuari Priambudi ${ }^{3)}$ \\ 1,2,3 Sekolah Vokasi, Universitas Diponegoro \\ Email: ${ }^{1}$ nofa.ariani@ live.undip.ac.id, ${ }^{2}$ indrahadiwijaya@live.undip.ac.id, \\ ${ }^{3}$ bagusnuaripriambudi@live.undip.ac.id ${ }^{3}$
}

\begin{abstract}
Abstrak
Pekalongan City is one of the cities with a batik cultural heritage preserved from tens or even hundreds of years ago. Most of the batik has been done by the community at home. Batik work, which has become the community's livelihood, slowly forms the peculiarities of regional spaces that can give an impression to visitors. This can be felt in an area known as Kampung Batik, one of which is Kampung Batik Kauman. Kauman Batik Village has now transformed into one of the cultural tourism destinations offered by the Pekalongan City Government. The uniqueness of the city space which is thick with culture and community activities is an attraction that is considered capable of providing tourist experiences and education related to batik production. This study analyzes the spatial area in Kampung Batik Kauman by using an unmeasured criteria analysis approach as a strong supporter to give an impression to observers. The results of the analysis show that Kampung Batik Kauman has met 6 (six) indicators of the unmeasured criteria although it needs improvement in several parts. The most powerful indicators are access, identity, and livability. The description of this analysis can be used as input for the Pekalongan City Government to increase its attractiveness and at the same time foster a love for urban space that has history and culture.
\end{abstract}

Keyword: Kampung batik, cultural heritage, unmeasured criteria

\section{PENDAHULUAN}

\subsection{Latar Belakang}

Budaya merupakan suatu kaidah hidup yang selalu berkembang, pun dimiliki bersama oleh suatu kelompok atau masyarakat tertentu, dan turun temurun pada suatu generasi. Budaya terbentuk dari beberapa unsur, di antaranya adat istiadat, sistem agama, perkakas, bangunan, karya seni, pakaian, dan bahasa (Tubbs, 2005). Budaya batik juga menjadi salah satu bagian budaya di Indonesia yang juga telah mendunia.

Kota Pekalongan merupakan kota kreatif di Indonesia dalam kategori kerajinan dan kesenian rakyat yang telah dinobatkan oleh UNESCO kemudian disusul Kota Bandung yang menjadi kota kreatif kedua dalam kategori design. Kota Pekalongan terkenal sebagai kota perdagangan batik dan sentra batik. Ekosistem ekonomi batik di Kota Pekalongan mempunyai 12.104 tenaga kerja yang tersebar di 760 unit usaha, pada industri canting terdapat 125 tenaga kerja, 50 unit usaha kain mori mempunyai 250 tenaga kerja, 25 unit usaha zat pewarna mempunyai 250 tenaga kerja, terdapat 525 unit usaha konveksi mempunyai 2.100 tenaga kerja, pada aksesoris konveksi mempunyai 50 tenaga kerja, produksi printing mempunyai 200 tenaga kerja, bordir mempunyai 50 tenaga kerja, terdapat 1.037 kios perdagangan batik mempunyai 3.111 tenaga kerja, limbah kain/perca mempunyai 125 tenaga kerja, 29 lembaga keuangan mikro mempunyai 145 tenaga kerja, serta ekspedisi mempunyai 250 tenaga kerja (Listiyaningrum, Rustiana, \& Saeroji, 2020).

Kota Pekalongan dalam mengembangkan budaya dan kerajinan batik didukung dengan adanya kampung batik, salah satunya adalah Kampung Wisata Batik Kauman. Kampung Wisata Batik Kauman sangat unik karena sebagian besar dimukim oleh pengrajin batik dan penjual batik, baik itu batik tulis ataupun 
batik cap, Pekalongan merupakan salah satu daerah produksi utama batik dengan desain utara Jawa pesisir, batik Pekalongan sudah dikenal antara abad XIV-XVI (Nasution, 2018). Berbagai sejarah dan budaya yang ada pada Kampung Batik Kauman tersebut, mendorong Pemerintah Kota Pekalongan untuk menetapkan kawasan Kampung Batik Kauman menjadi destinasi wisata budaya.

Pengembangan destinasi wisata budaya tidak terlepas dari adanya perhatian terhadap kualitas ruang itu sendiri. Adanya "value" yang ditawarkan pada sebuah kawasan akan memberikan dampak tersendiri yang membedakan dengan kawasan lainnya. Penelitian ini akan mempelajari tentang sejauh mana kualitas ruang Kampung Batik Kauman yang akan dianalisis menggunakan analisis kriteria tak terukur.

\subsection{Rumusan Masalah}

Kota Pekalongan merupakan salah satu kota dengan industri kreatif yang berkembang melalui industri dan kerajinan batik, sehingga Kota Pekalongan telah ditetapkan menjadi kota kreatif dunia (Iglesias, 2014). Berdasarkan hal tersebut maka Kota Pekalongan telah menggabungkan industri batik dengan aktivitas wisata melalui pariwisata kreatif (Damayanti \& Latifah, 2015). Kawasan yang identik dengan perkembangan industri batik yang mengarah ke pariwisata kreatif salah satunya adalah Kampung Batik Kauman. Sentra industri Batik Kauman juga merupakan sentra batik tertua di Kota Pekalongan yang mendorong bangkitnya sentra batik yang ada di sekitar seperti Sentra Batik Medono atau Kampung ATBM Medono (Andriani, Astuti, \& Putri, 2020).

Perkembangan pariwisata terutama di Indonesia telah mengalami pergeseran paradigma. Perubahan paradigma pariwisata salah satunya disebabkan oleh wisatawan yang membutuhkan untuk dapat lebih interaktif dan berusaha memenuhi pengalaman bukan hanya sekedar menjadi wisatawan yang dilayani oleh industri pariwisata (Tan, Luh, \& Kung, 2014). Kampung Batik Kauman seakan memenuhi keinginan para wisatawan yang ingin pengalaman lebih dalam melakukan perjalanan wisata. Pengalaman ini didapatkan dari pengamatan kawasan, interaksi dengan masyarakat sampai mencoba pengalaman baru untuk menjadi pembatik.

Daya tarik yang diinginkan oleh wisatawan menjadi salah satu indikator dalam memperbaiki kualitas ruang fisik dan non fisik pada Kampung Batik Kauman. Aspek non fisik yang lebih menekankan kepada "rasa" juga cukup penting untuk ditingkatkan. Potensi bangunan kuno, wajah kawasan, sampai tradisi membatik masyarakat belum terlihat menonjol. Salah satu analisis yang dapat dilakukan untuk meningkatkan aspek non fisik kawasan adalah dengan mengkaji nilai dan kualitas ruang pada Kampung Batik Kauman. Berdasarkan latar belakang yang telah dijabarkan sebelumnya, maka muncul pertanyaan penelitian "Bagaimana nilai dan kualitas ruang kawasan Kampung Batik Kauman Kota Pekalongan sebagai kawasan wisata budaya?"

\subsection{Tujuan Penelitian}

Pengembangan kawasan wisata pada suatu daerah tidak lepas dari berbagai faktor terhadap lokasi wisata itu sendiri. Faktor yang dimaksud dapat berupa faktor fisik dan non fisik. Kampung Batik Kauman menjadi salah satu kawasan bersejarah yang mampu memberikan kontribusi terhadap perkembangan Kota Pekalongan, baik secara ekonomi, sejarah, maupun budaya. Permasalahan yang muncul terkait potensi Kampung Batik Kauman untuk berkembang menjadi pariwisata budaya yang kreatif, mendorong peneliti untuk mengkaji secara lebih jauh aspek non fisik kawasan.

Penelitian ini bertujuan untuk mengevaluasi nilai dan kualitas ruang kawasan wisata budaya Kampung Batik Kauman yang dapat memberikan "value" yang tidak hanya menyangkut daya tarik wisata tetapi juga mengangkat nilai sejarah kawasan. Diharapkan dengan hasil studi ini dapat memberikan pandangan guna meningkatkan potensi Kampung Batik Kauman.

\section{METODE PENELITIAN}

Penelitian ini bertujuan untuk melihat sejauh mana ruang-ruang kawasan yang terbentuk jika dilihat dari aspek non fisik. Metode penelitian berupa deskriptif kualitatif berdasarkan pengamatan lapangan dan data sekunder. Kendala yang dihadapi pada 
penelitian ini terkait dengan metode pengumpulan data yang tidak bisa dilakukan secara primer, mengingat kondisi pandemi dan pemberlakuan PPKM (Pemberlakuan Pembatasan Kegiatan Masyarakat). Data yang didapatkan berdasarkan pengalaman peneliti pada kawasan Kampung Batik Kauman dilengkapi dengan data sekunder melalui Google Steet View.

Penelitian ini melihat kualitas ruang kawasan menggunakan indikator yang diungkapkan oleh Hamid Shirvani (1985) tentang kriteria tak terukur:

1) Access (Pencapaian). Pencapaian dapat ditunjukkan dari kemudahan, kenyamanan, dan keamanan dalam mencapai tujuan.

2) Compatibility (Kecocokan). Compatibility merupakan kecocokan tata letak dengan topografi, bentuk dan massa bangunan, dan skala. Compatibility terfokus pada estetika dan arsitektur. Di samping itu, aspek lain yang harus diperhatikan adalah sejarah, budaya, dan komponen yang cocok dengan nilai bangunan.

3) Views (Pemandangan). Views merupakan kejelasan antara orientasi manusia terhadap massa bangunan yang dapat ditunjukkan oleh adanya suatu landmark yang dapat menjadi ciri khas atau sesuatu yang menarik pada kawasan tertentu. Evaluasi estetika dapat dilihat dari skala dan pola bangunan, penggunaan warna, tekstur, tinggi, besaran dan bentuk dari objek yang diamati.

4) Identity (Identitas). Identity merupakan suatu ciri yang dapat dikenali oleh pengamat (citra). Elemen ini dapat dikenali melalui landmark dari suatu kawasan yang dapat mencirikan identitas dari kawasan tersebut.

5) Sense (Rasa). Sense adalah suasana yang ditimbulkan masih berhubungan dengan aspek budaya. Kriteria ini dapat dicapai dengan desain bentuk yang khusus atau suatu kegiatan yang dapat menyentuh hati masyarakat, merupakan rangkaian ruang yang memiliki fungsi erat, dan berkaitan dengan kegiatan sosial maupun proses alami.
6) Livability (Kehidupan). Merupakan kenyamanan untuk tinggal di dalamnya bagi banyak orang yang masuk di dalamnya. Untuk mengetahui tingkat kenyamanan tinggal di dalamnya, dibutuhkan indikator kenyamanan agar memiliki persepsi yang sama.

\section{HASIL DAN PEMBAHASAN \\ 3.1. Peran Kampung Batik Kauman Terhadap Kota Pekalongan \\ Pekalongan merupakan salah satu daerah} produksi utama batik dengan desain utara Jawa pesisir, batik Pekalongan sudah dikenal antara abad XIV-XVI dengan diketemukannya pola grinsing dan banji, sebagian besar batik yang diproduksi dalam motif warna-warni dipengaruhi oleh Cina Arab dan Belanda. Ada lebih dari 100 desain Batik yang sudah dikembangkan sejak 1802. Para seniman memiliki ribuan ide-ide dalam mendesain motif batik tanpa sesuai pakem motif tradisional, misalnya, selama pendudukan Jepang mereka menciptakan Javanese Kokokai yaitu motif batik yang cocok untuk jaket kimono. Pada tahun enam puluhan mereka menciptakan Tritura Batik (Nasution, 2018).

Kawasan Kampung Batik Kauman merupakan kampung tertua, yang ada di kawasan Pekalongan mengingat di Kampung Kauman banyak ditemukan rumah-rumah kuno peninggalan di masa lalu dan Masjid Jami' yang didirikan tahun 1852 (Center, 2021). Selain itu, arsitektur rumah-rumah lawas tempat tinggal perajin dari generasi ke generasi juga menjadi daya tarik tersendiri. Dugaan Kampung Batik Kauman sebagai kampung tertua di Kota Pekalongan makin kuat setelah ditemukan batik yang merupakan perpaduan batik Arab dengan India yang disebut Batik Jlampang dan batik pengaruh dari Cina yang disebut Batik Encim yang telah lama di Kampung Batik Kauman (Center, 2021).

Berdasarkan penjelasan tersebut bahwa Kampung Batik Kauman memiliki peran yang sangat kuat terhadap Kota Pekalongan. Kampung Batik Kauman menjadi identitas, sekaligus menjadi destinasi wisata yang dapat dikembangkan. Pada sisi lainnya, produksi kerajinan batik dapat memberikan nilai 
ekonomi baik untuk masyarakat maupun untuk Kota Pekalongan.

\subsection{Analisis Nilai dan Kualitas Ruang Menggunakan Pendekatan Kriteria Tak Terukur \\ Pengamatan nilai dan kualitas ruang juga} sejalan dengan makna dari human space, di mana ruang dilihat dari sisi "rasa", karena ada ikatan kuat antara ruang dan makna. Kota merupakan wadah aktivitas penduduk yang memiliki nilai budaya, sejarah maupun hal-hal lain yang sifatnya kontekstual. Keunikan, ciri khas suatu kota tidak lepas dari perkembangan sejarah, budaya dan nilai sosial yang ada dalam komunitas kota tersebut. Bentukan/rancangan kota harus dapat merespon dan mewadahi nilai sosial, budaya, persepsi visual, sehingga kota tidak hanya hadir dan dirasakan sebagai space, namun juga dapat dirasakan keberadaannya sebagai sebuah place (Trancik, 1986).

Pengamatan terhadap kualitas ruang Kampung Batik Kauman, akan menjabarkan makna dari kawasan, kekhasan serta nilai budaya yang ada dan melekat. Terdapat 6 (enam) indikator untuk menilai ruang kawasan pada Kampung Batik Kauman:

7) Access (Pencapaian)

Kampung Batik Kauman terletak di Kelurahan Kauman, yang merupakan salah satu kelurahan yang masuk dalam administrasi Kecamatan Pekalongan Timur, Kota Pekalongan. Letak kampung ini sangat strategis, karena berada pada pusat Kota Pekalongan dan terletak di sebelah barat Alun-alun Kota Pekalongan. Kampung ini bisa diakses dari Jalur Pantura dan permukiman masyarakat Kampung Batik Kauman tepat berada di belakang masjid bersejarah, yaitu Masjid Jami' Pekalongan. Terdapat 2 (dua) pintu masuk untuk menuju Kampung Batik Kauman (Gambar 1).

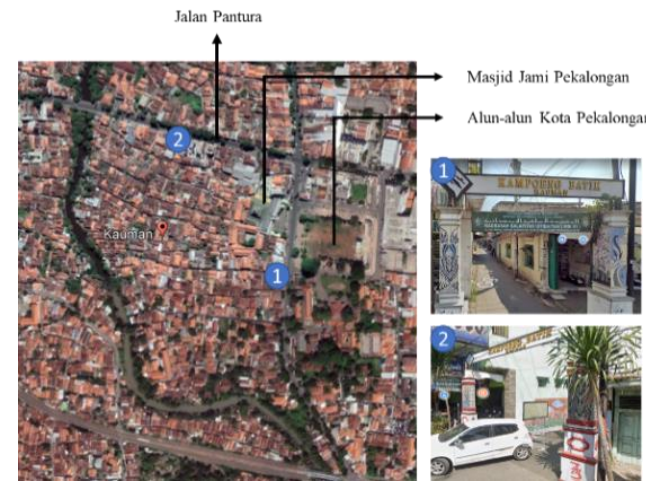

Sumber: Identifikasi Penyusun, 2021

Gambar 1 Pencapaian Menuju Kampung Batik Kauman

\section{8) Compatibility (Kecocokan)}

Kampung Kauman yang merupakan kampung dengan sejarah dan budaya yang turun temurun, ditunjukkan dengan adanya bangunan-bangunan lawas peninggalan zaman penjajahan (Gambar 2). Bangunanbangunan tersebut sampai sekarang masih terawat, dan berdampingan dengan permukiman modern milik masyarakat saat ini. Walaupun bangunan lawas hanya tampak pada beberapa tempat, namun letak bangunan ini tidak terasa asing walaupun disandingkan dengan permukiman warga. Terdapat kecocokan dan "rasa khas" yang muncul karena menunjukkan bahwa budaya sekaligus gaya arsitektur lawas sangat melekat dengan kawasan ini.

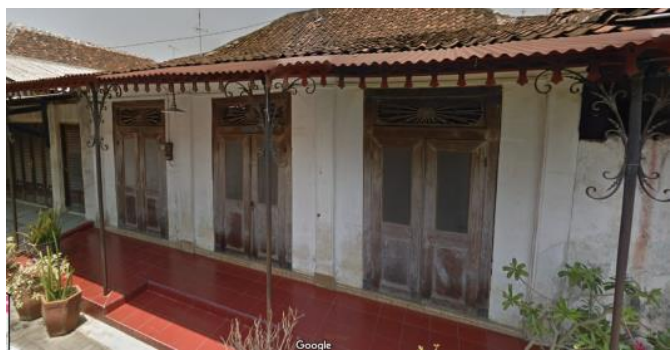

Sumber: Survey Sekunder Google Street View, 2021

Gambar 2 Bangunan Lawas Pada Kampung Batik Kauman

9) Views (Pemandangan)

Pemandangan pada Kawasan Kampung Batik Kauman terlihat hampir pada seluruh kawasan. Pemandangan ini berupa adanya permukiman-permukiman warga dengan banner atau papan penanda toko pakaian batik, kain batik, tas, sandal, dan produk kerajinan batik lainnya (Gambar 3). 
Banyaknya toko dan produsen batik menjadi daya tarik bagi pengunjung untuk melihat atau pun membeli hasil-hasil kerajinan batik. Pemandangan ini menjadi sangat berarti karena Kampung Batik Kauman adalah kampung wisata budaya dengan peninggalan batiknya.

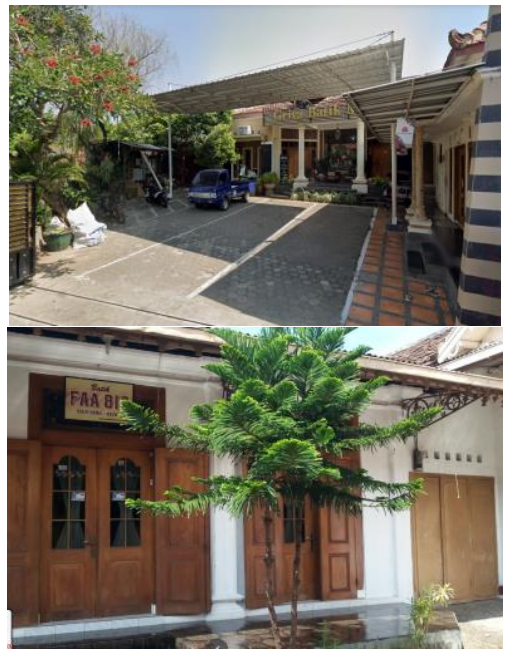

Sumber: Survey Sekunder Google Street View, 2021

Gambar 3 Toko Penjualan Produk Kerajinan Batik

\section{0) Identity (Identitas)}

Kampung Batik Kauman yang diduga sebagai kampung tertua yang ada di Kota Pekalongan memiliki identitas yang sangat kuat. Identitas ini ditunjukkan dengan adanya Masjid Jami' Pekalongan yang merupakan masjid bersejarah dan menjadi icon sekaligus identitas Kampung Kauman bahkan Kota Pekalongan. Identitas lain yang ditunjukkan adalah adanya "Showroom Bersama Kampung Batik Kauman" yang merupakan penciri bahwa batik telah menjadi bagian dari masyarakatnya yang sebagian besar merupakan pengrajin. Kedua identitas tersebut ditunjukkan pada gambar berikut.

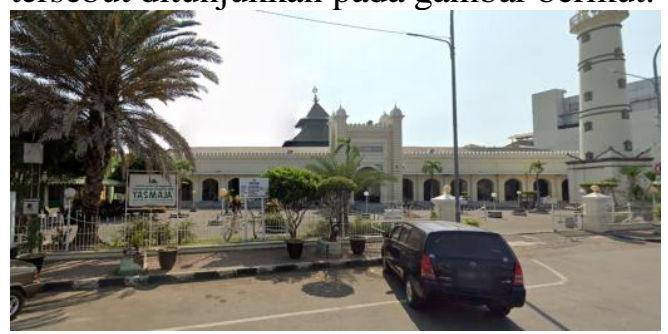

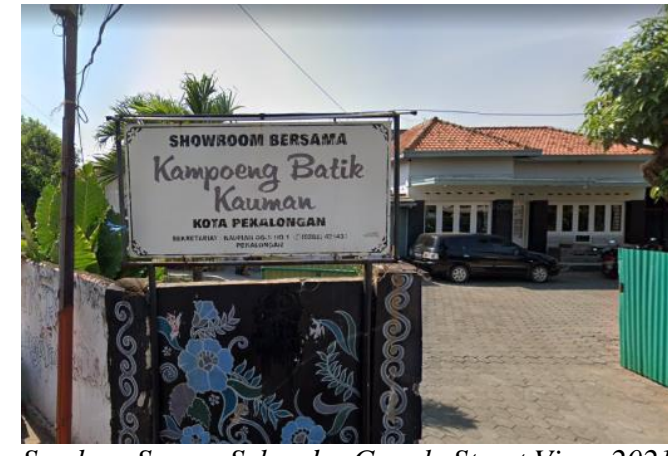

Sumber: Survey Sekunder Google Street View, 2021

Gambar 4 Identitas Kampung Batik Kauman

11) Sense (Rasa)

Sense adalah suasana yang ditimbulkan masih berhubungan dengan aspek budaya. Rasa yang dimunculkan ketika masuk ke dalam kawasan ini dirasa belum cukup kuat, karena sebagian besar permukiman sudah mencirikan permukiman modern dan aktivitas pengrajin tidak secara terbuka tampak. Namun rasa adanya budaya batik ini cukup terasa pada beberapa bagian kawasan yang ditunjukkan dengan adanya mural-mural dan corak-corak batik pada dinding-dinding kawasan (Gambar 5). Sayangnya, mural atau lukisan batik ini sudah mulai memudar sehingga perlu adanya kreasi dan inovasi lagi untuk memunculkan tampilan ini sebagai daya tarik khususnya untuk kaum millennial yang sangat tertarik dengan sosial media.

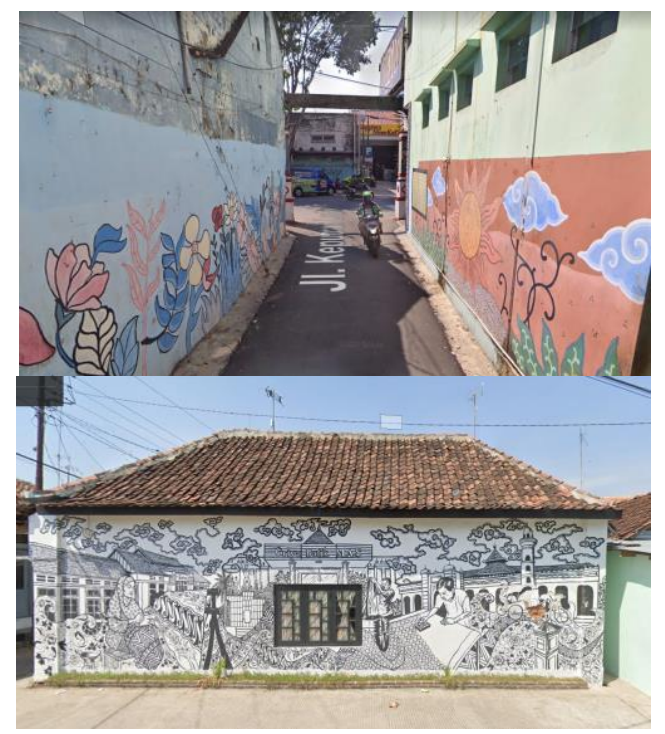

Sumber: Survey Sekunder Google Street View, 2021

Gambar 5 Mural dan Corak Batik Pada Dinding Bangunan 


\section{2) Livability (Kehidupan)}

Daya tarik yang sekaligus dapat menggambarkan kehidupan masyarakat Kampung Batik Kauman adalah kegiatan masyarakat dalam memproduksi batik. Saat ini, pengunjung maupun wisatawan diberi kesempatan untuk mengunjungi lokasi-lokasi para pengrajin batik untuk melihat dan belajar membatik (Gambar 6) Hal ini tentu saja menjadi daya tarik penting yang ditawarkan, dan berbeda dengan kampung batik lainnya. Kehidupan masyarakat yang sebagian besar merupakan para pengrajin batik membuat kehidupan masyarakat Kauman mencirikan budaya yang terampil dan juga religius. Di samping para pengrajin batik, masyakat juga sangat kental dengan kegiatankegiatan masyarakat seperti pengajian atau acara keagamaan lainnya.

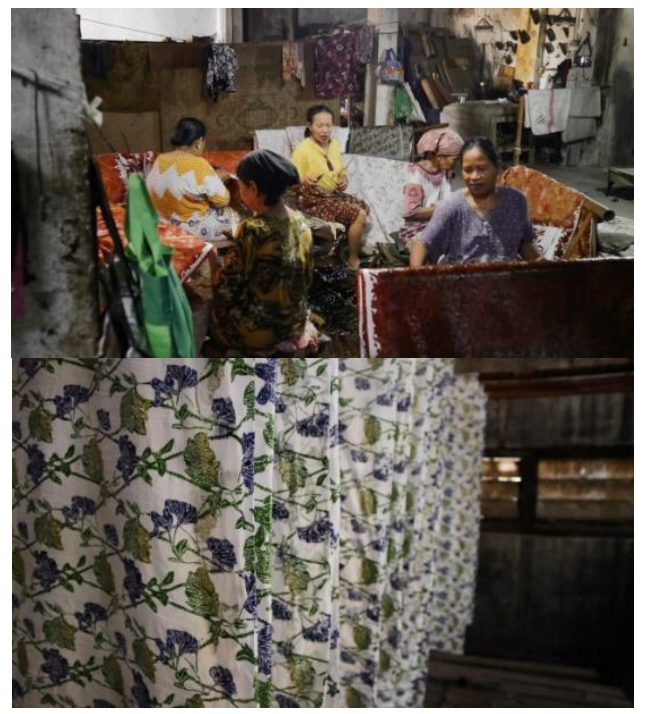

Sumber: Tukang Ngider, 2020

Gambar 6 Kegiatan Pengrajin Batik
Kegiatan industri batik di Kampung Batik Kauman pada umumnya masih dikelola dengan sistem tradisional dan kekeluargaan. Kebiasaan ini berpadu dengan pengerjaan Batik Pekalongan yang tersebar di rumah-rumah penduduk membuat Batik Pekalongan menyatu erat dan menjadi bagian dari kehidupan masyarakatnya. Batik juga menjadi salah satu penopang perekonomian utama bagi masyarakat Kampung Kauman (Isnaeni, 2020).

Kampung Batik Kauman, sebagai salah satu kampung batik yang sekaligus menjadi destinasi wisata budaya dapat dikembangkan menjadi pusat destinasi unggul di Kota Pekalongan. Analisis ini dapat menjadi rujukan dan masukan terhadap berbagai kekurangan terutama dari segi kualitas ruang untuk menghasilkan "value" agar lebih banyak wisatawan yang dapat berkunjung. Keberadaan dan eksistensi Kampung Batik Kauman tidak terlepas dari berbagai peran stakeholder baik dari pemerintah, investor, media, dan masyarakat.

Gambaran tentang evaluasi analisis kriteria tak terukur dapat disimpulkan dengan mengkaji potensi permasalahan pada setiap aspek sehingga dapat dirumuskan program yang tepat untuk meningkatkan setiap aspeknya. Tabel 1 merupakan sintesis dari evaluasi di setiap aspek pada kriteria tak terukur Kampung Batik Kauman Kota Pekalongan. 
Tabel 1 Sintesis Analisis Kriteria Tak Terukur

\begin{tabular}{|c|c|c|c|c|}
\hline No & $\begin{array}{c}\text { Aspek Kriteria Tak } \\
\text { Terukur } \\
\end{array}$ & Aspek Menonjol & Kelemahan & $\begin{array}{c}\text { Rujukan Program } \\
\text { Pengembangan }\end{array}$ \\
\hline 1 & Access (Pencapaian) & $\begin{array}{l}\text { Letak kampung ini sangat } \\
\text { strategis, karena berada pada } \\
\text { pusat Kota Pekalongan dan } \\
\text { terletak di sebelah barat } \\
\text { Alun-alun Kota Pekalongan. } \\
\text { Kampung ini bisa diakses } \\
\text { dari Jalur Pantura }\end{array}$ & $\begin{array}{l}\text { Tidak ada kelemahan } \\
\text { dari aspek ini, tidak } \\
\text { ada hambatan yang } \\
\text { berarti dalam } \\
\text { mencapai lokasi }\end{array}$ & $\begin{array}{l}\text { Pengembangan rute } \\
\text { angkutan dari dan menuju } \\
\text { lokasi dengan peta destinasi } \\
\text { wisata agar memudahkan } \\
\text { para wisatawan untuk } \\
\text { berkunjung }\end{array}$ \\
\hline 2 & $\begin{array}{l}\text { Compatibility } \\
\text { (Kecocokan) }\end{array}$ & $\begin{array}{l}\text { Adanya kecocokan yang } \\
\text { tampak pada lokasi studi } \\
\text { yang ditunjukkan dengan } \\
\text { adanya bangunan-bangunan } \\
\text { lawas peninggalan sejarah } \\
\text { yang sesuai dengan tema } \\
\text { wisata budaya }\end{array}$ & $\begin{array}{l}\text { Perlunya perawatan } \\
\text { dan konservasi } \\
\text { terhadap bangunan- } \\
\text { bangunan yang } \\
\text { dianggap mencirikan } \\
\text { sejarah kawasan }\end{array}$ & $\begin{array}{l}\text { Pemugaran dan perawatan } \\
\text { terhadap bangunan- } \\
\text { bangunan lawas serta } \\
\text { bangunan lain yang dapat } \\
\text { meningkatkan nilai sejarah } \\
\text { kawasan }\end{array}$ \\
\hline 3 & Views (Pemandangan) & $\begin{array}{l}\text { Pemandangan yang } \\
\text { ditunjukkan pada Kampung } \\
\text { Batik Kauman ini cukup kuat. } \\
\text { Pemandangan yang dimaksud } \\
\text { berupa adanya permukiman- } \\
\text { permukiman warga dengan } \\
\text { banner atau papan penanda } \\
\text { toko pakaian batik, kain } \\
\text { batik, tas, sandal, dan produk } \\
\text { kerajinan batik lainnya }\end{array}$ & $\begin{array}{l}\text { Pemandangan ini perlu } \\
\text { lebih ditata melalui } \\
\text { pengaturan bangunan } \\
\text { dan jenis kegiatannya } \\
\text { agar para pengunjung } \\
\text { mendapatkan } \\
\text { pengalaman yang } \\
\text { lengkap saat masuk ke } \\
\text { kawasan. }\end{array}$ & $\begin{array}{l}\text { Penataan bangunan dan } \\
\text { kegiatan kawasan dengan } \\
\text { penyusunan dokumen } \\
\text { RTBL Kampung Batik } \\
\text { Kauman }\end{array}$ \\
\hline 4 & Identity (Identitas) & $\begin{array}{l}\text { Terdapat } 2 \text { (dua) identitas } \\
\text { yang kuat yaitu Masjid Jami' } \\
\text { Pekalongan dan "Showroom } \\
\text { Bersama Kampung Batik } \\
\text { Kauman" }\end{array}$ & $\begin{array}{l}\text { Tidak ada kelemahan } \\
\text { pada aspek ini, kedua } \\
\text { identitas telah } \\
\text { menggambarkan } \\
\text { wilayah studi }\end{array}$ & $\begin{array}{l}\text { Penggunaan identitas } \\
\text { sebagai landmark kawasan } \\
\text { dalam pengembangan } \\
\text { kawasan wisata budaya } \\
\text { Kampung Batik Kauman }\end{array}$ \\
\hline 5 & Sense (Rasa) & $\begin{array}{l}\text { Rasa yang menggambarkan } \\
\text { budaya batik ini cukup terasa } \\
\text { pada beberapa bagian } \\
\text { kawasan yang ditunjukkan } \\
\text { dengan adanya mural-mural } \\
\text { dan corak-corak batik pada } \\
\text { dinding-dinding kawasan }\end{array}$ & $\begin{array}{l}\text { Mural dan corak-corak } \\
\text { batik ini hanya terlihat } \\
\text { pada beberapa bagian } \\
\text { kawasan saja dan } \\
\text { sudah tampak } \\
\text { memudar. Dominasi } \\
\text { nuansa perkotaan } \\
\text { perlahan membuat rasa } \\
\text { budaya yang ada } \\
\text { perlahan hilang }\end{array}$ & $\begin{array}{l}\text { Perawatan dan } \\
\text { pengembangan karya seni } \\
\text { batik melalui mural dan } \\
\text { kerajinan batik lainnya } \\
\text { dapat dimunculkan pada } \\
\text { sebagian besar kawasan } \\
\text { dengan mengangkat tema- } \\
\text { tema tertentu. Hal tersebut } \\
\text { sebagai upaya } \\
\text { menumbuhkan kecintaan } \\
\text { terhadap batik dan para } \\
\text { pengrajinnya. }\end{array}$ \\
\hline 6 & $\begin{array}{l}\text { Livability } \\
\text { (Kehidupan) }\end{array}$ & $\begin{array}{l}\text { Kehidupan masyarakat yang } \\
\text { sebagian besar merupakan } \\
\text { para pengrajin batik membuat } \\
\text { kehidupan masyarakat } \\
\text { Kauman mencirikan budaya } \\
\text { yang terampil dan juga } \\
\text { religius. Di samping para } \\
\text { pengrajin batik, masyarakat } \\
\text { juga sangat kental dengan } \\
\text { kegiatan-kegiatan masyarakat } \\
\text { seperti pengajian atau acara } \\
\text { keagamaan lainnya. }\end{array}$ & $\begin{array}{l}\text { Tidak ada kelemahan } \\
\text { dalam aspek ini, } \\
\text { karena aspek ini } \\
\text { termasuk yang cukup } \\
\text { kuat di Kampung } \\
\text { Batik Kauman }\end{array}$ & $\begin{array}{l}\text { Pengembangan paguyuban } \\
\text { pengrajin dan peningkatan } \\
\text { partisipasi masyarakat } \\
\text { pengrajin dalam } \\
\text { meningkatkan daya tarik } \\
\text { wisata budaya Kampung } \\
\text { Batik Kauman. }\end{array}$ \\
\hline
\end{tabular}




\section{SIMPULAN DAN SARAN}

\subsection{Simpulan}

Berdasarkan penjabaran dari analisis yang telah dilakukan, maka dapat disimpulkan berbagai hal antara lain:

1) Indikator kriteria tak terukur yang paling kuat adalah access, identity dan livability. Access dalam hal ini sangat kuat, karena letak Kampung Batik Kauman yang ada tepat di sebelah barat alun-alun kota, terletak di pusat kota dan sangat mudah dicapai dari berbagai penjuru kota. Identity merupakan identitas penciri warisan budaya sekaligus bukti peninggalan sejarah berupa masjid dan identitas kampung batik berupa showroom. Livability merupakan kehidupan yang tentunya sangat melekat dengan masyarakat yaitu membatik dan memproduksi kerajinan batik, serta kegiatan kemasyarakatan lainnya yang menunjukkan sisi religius masyarakat.

2) Indikator lain yang dapat menjadi masukan dalam meningkatkan nilai kualitas ruang pada Kampung Batik Kauman adalah compatibility, views, dan sense. Compatibility terkait dengan kecocokan bangunan bersejarah dengan permukiman warga saat ini. Kecocokan ini akan lebih kuat jika bangunan-bangunan lama dipugar dan dirawat agar tampilan tetap terlihat menarik dan tidak timpang dengan bangunan modern. Pada views, dirasa perlu adanya penyeragaman karakter papan penanda agar rasa tertata, teratur dan indah didapatkan. Pada sense, diperlukan lebih banyak mural-mural atau inovasi-inovasi pada kawasan yang mencirikan kawasan sekaligus dapat menciptakan rasa "menyatu" dengan kawasan.

\subsection{Saran}

Pengamatan terhadap nilai dan kualitas ruang memberikan gambaran awal terhadap potensi yang dimiliki oleh Kampung Batik Kauman untuk berkembang menjadi destinasi wisata budaya. Pada perjalanannya, diperlukan studi-studi lanjutan untuk memperkaya muatan dan indikator lain untuk merumuskan program yang dapat dilakukan Pemerintah Kota
Pekalongan. Adapun saran untuk penelitian lanjutan antara lain:

1) Studi kajian partisipasi masyarakat Kampung Batik Kauman terhadap perkembangan wisata Kota Pekalongan;

2) Analisis faktor daya tarik wisata Kampung Batik Kauman;

3) Analisis pola ruang dan zonasi Kampung Batik Kauman; dan

4) Analisis arahan Urban Design kawasan Kampung Batik Kauman.

\subsection{Rekomendasi}

Pengembangan sebuah kawasan wisata tidak lepas dari peran stakeholder, di antaranya adalah pemerintah, swasta, masyarakat serta media. Berdasarkan penelitian terhadap nilai dan kualitas ruang yang ada di Kampung Batik Kauman, maka rekomendasi yang dapat diberikan kepada pemerintah Kota Pekalongan adalah:

1) Program Penataan Kawasan Kampung Batik Kauman sebagai Kawasan Wisata Budaya

2) Penyusunan dokumen RTBL (Rencana Tata Bangunan dan Lingkungan) Kawasan Kampung Batik Kauman

3) Penyusunan Masterplan Kawasan Wisata Kota Pekalongan;

4) Program Peningkatan Kualitas Daya Tarik Wisata Kampung Batik Kauman melalui CSR; dan

5) Pembentukan Pokdarwis (Kelompok Sadar Wisata) Kampung Batik Kauman.

\section{REFERENSI}

Andriani, R., Astuti, W., \& Putri, R. A. (2020). Peran Sentra Batik Kauman Dan Pesindon Untuk Mencapai Kota Pekalongan Sebagai Kota Kreatif Kerajinan. Desa Kota, 203 216.

Center, B. \&. (2021, Juli 23). Kampung Batik Kauman. Retrieved from Badan Promosi Pariwisata Kota Pekalongan: http://tourism.pekalongankota.go.id/destin asi/2-Kampung\%20Batik\%20Kauman

Damayanti, M., \& Latifah. (2015). Strategi Kota Pekalongan Dalam Pengembangan 
Wisata Kreatif Berbasis Industri Batik. Jurnal Pengembangan Kota, 100-111.

Iglesias, L. (2014). www. unesco.org. Retrieved from 28 cities join the UNESCO Creative Cities Network: http://www.unesco.org/new/en/mediaservices/singleview/news/28_cities_join_the_unesco_cre ative_cities_network/\#.VPx6g-EVT3t

Isnaeni, I. (2020, Agustus 21). Sejarah Kampung Batik Kauman, Kota Pekalongan. Retrieved from Kompasiana: https://www.kompasiana.com/iinisnaeni10 99/5f3f699d097f36541955f5c4/sejarahkampung-batik-kauman-kotapekalongan?page $=$ all

Kampung Batik Kauman: Tertua Di Pekalongan. (2020, Juli 29). Retrieved from Tukang Ngider: https://tukangngider.com/kampung-batikkauman-tertua-di-pekalongan/

Listiyaningrum, A., Rustiana, A., \& Saeroji, A. (2020). Strategi Pengembangan Batik Berbasis Ekonomi Kreatif Kampung Batik Kauman Pekalongan. Business and Accounting Education Journal, 116-127.

Nasution, D. Z. (2018). Citra Destinasi Melalui Film: (Studi Kasus Kampung Wisata Batik Kauman Pekalongan. Jurnal Ilmiah Pariwisata, 10-20.

Shirvani, Hamid. 1985. The Urban Design Process. Van Nostrand Reinhold: New York.

Tan, S. K., Luh, D. B., \& Kung, S. F. (2014). A taxonomy of creative tourists in creative tourism. Tourism Management, 248-259. doi:http://dx.doi.org/10.1016/j.tourman.20 13.11.008

Trancik, R. (1986). Finding Lost Spaces: Theories of Urban Design. USA: John Wiiley and Sons.

Tubbs, S. L. (2005). Human Communication, Buku 2: Konteks-konteks Komunikasi. Bandung: Remaja Rosdakarya. 